\title{
Vivir con ruido en la Ciudad de México. El proceso de adaptación a los entornos acústicamente hostiles
}

\author{
Ana Lidia M. Domínguez Ruiz*
}

La propuesta que aqui se presenta es producto de una investigación doctoral antropológica recién concluida titulada "La naturaleza sonora de la vida urbana. Ruido, convivencia y conflicto por el espacio sonoro en la Ciudad de México", cuyo objeto general de estudio ha sido el análisis del fenómeno del ruido más allá de su dimensión estética, es decir, como construcción social producto de la interrelación de factores espaciales, demográficos, psicológicos, culturales e históricos, definidos por el modo de vida urbano.

En este marco de reflexiones, el análisis del proceso de adaptación en tanto fenómeno fundador de las relaciones ambientales constituye una prioridad, pues permite comprender los procesos de ajuste y desajuste entre el entorno urbano y sus habitantes. Especificamente, al hablar del ruido se pretende conocer las diversas maneras en que esta relación se ha desarrollado no sólo por vía de la atrofia sensorial, sino a través de diversas técnicas de construcción de la vida cotidiana, donde alcanzar la normalidad es una situación patológica de la vida en las grandes ciudades como México.

Palabras clave: Ciudad de México, ruido, habituación, sensibilización, vida cotidiana, problemas urbanos.

Fecha de recepción: 3 de mayo de 2012.

Fecha de aceptación: 28 de febrero de 2013.

\section{Living with Noise in Mexico City. The Process of Adaptation to Acoustically Hostile Environments}

The proposal presented here is the result of a recently completed anthropological doctoral research project entitled "The aural aspect of urban life. Noise, coexistence and conflict over the soundscape in Mexico City." The general purpose of the study was to analyze the phenomenon of noise beyond its aesthetic dimension, in other words, as a social construction resulting from the interrelationship between spatial, demographic, psychological, cultural and historical factors, defined by the urban lifestyle.

Within this framework of reflections, the analysis of the adaptation process as a founding phenomenon of environmental relations is a priority, as it explains the match and mismatch between the urban environment and its inhabitants. Specifically, in speak-

* Profesora de tiempo completo de la Universidad Pedagógica Nacional. Correo electrónico:<unalaid@hotmail.com>. 
ing of the noise, the aim is to find out about the various ways in which this relationship has been developed not only via sensory atrophy, but also through various techniques for constructing everyday life, where achieving normality is a pathological situation of life in large cities such as Mexico City.

Key words: Mexico City, noise, habituation, sensitization, everyday life, urban problems.

\section{Introducción}

La adaptación al entorno se considera un proceso no sólo natural sino deseable, en tanto supone la mutua domesticación entre el ser humano y el espacio que habita. La construcción de la normalidad cotidiana es un proceso paulatino de ajuste que, a fuerza de costumbre, permite al individuo liberar a sus sentidos del sobresalto que provocan las primeras impresiones. Adaptarse también implica la modificación del entorno a partir de las posibilidades que éste proporciona, con la intención de hacerlo a nuestro modo e incorporar la extrañeza del mundo a nuestra vida hasta hacerla familiar.

La historia de la humanidad es un continuum de procesos adaptativos -lentos, rápidos, abruptos, devastadores, creativos-. En este recuento es posible considerar a "la ciudad" como el culmen de la adaptación; este portento del artificio humano ha supuesto un sinnúmero de dramáticas transformaciones al mundo natural, dando lugar a eso que se conoce como modo de vida urbano y que incluye una amplia gama de fenómenos distintivos tales como la organización económica, la disposición espacio-temporal, las estrategias y los medios de comunicación e interacción social, el estilo de vida, las formas de pensamiento, e incluso, a decir de George Simmel (1988), ha dado lugar a un nuevo tipo de individuo que denomina "urbanita".

Uno de los tantos fenómenos que ha engendrado la vida urbana, y que constituye el objeto de análisis de este trabajo, es el ruido. El ruido $^{2}$ es el referente sonoro de la dinámica urbana, producto de una

1 Según Simmel, el habitante de las ciudades posee una personalidad regida por la racionalidad económica, que antepone su libertad individual a las onerosas exigencias sociales, y que utiliza la actitud de reserva o contención como estrategia para enfrentar la realidad fragmentaria, transitoria y sobrecargada de estímulos de las grandes ciudades.

${ }^{2}$ Comúnmente se define al ruido como contaminación acústica, sin embargo esta definición está muy lejos de encarnar la complejidad de dicho fenómeno porque alude a todo y a nada al mismo tiempo. Justo la exploración de esta complejidad ha sido el 
ciudad que se mueve y cuyo movimiento es indispensable para que ésta funcione. Hoy día, este fenómeno domina el paisaje sonoro de las grandes ciudades, configurando un entorno saturado no sólo de altos volúmenes, sino de una presencia sonora continua que no da tregua, un paisaje invadido por sonoridades producto de una vida altamente tecnologizada, de un mundo portátil que permite individualizar el sonido, de alarmas que atestiguan el creciente temor a la inseguridad, de altos volúmenes cuyo poder abarcativo pareciera necesario para comunicarse con las masas, de un ritmo de vida que privilegia el tiempo productivo sobre el descanso.

Este panorama acústicamente hostil ha comenzado a pasar factura a sus habitantes: organismos estresados, oídos acechados, mentes cansadas, personas indiferentes. Curiosamente, el ciudadano no siempre repara en los costos del ruido, e incluso llega a someterse gustosamente a los deleites del poder sonoro. Justo esta inadvertencia es el más poderoso indicador de que el ruido ha llegado a niveles preocupantes: estamos dejando de escuchar -entendiendo esta acción en su más amplio sentido: oír y comprender.

La pérdida de las capacidades de escucha es el resultado del proceso adaptativo, es decir, se trata del precio que los habitantes de las ciudades han tenido que pagar para construir su ansiada normalidad cotidiana. Así vista, la adaptación no parece un fenómeno siempre conveniente, en tanto que ha implicado la asimilación de un medio adverso y la realización de ajustes forzosos que han modificado las capacidades del cuerpo ciudadano, que es ante todo un cuerpo social. Este hecho contribuye a reforzar una idea que ha estado históricamente presente en las reflexiones en torno a la ciudad, y que es la existencia de cierto grado de nocividad inherente al modo de vida urbano.

El presente trabajo tiene el objetivo de comprender el proceso de adaptación de los habitantes de la Ciudad de México a su entorno sonoro, a través del análisis de una serie de situaciones relacionadas con la presencia del ruido en la vida cotidiana. La información que aparece en las siguientes páginas ha sido recogida a través de entrevistas formales e informales, planeadas con la intención de conocer la experiencia de ciertos personajes urbanos cuyas formas de vida pueden vincularse a su condición vulnerable con respecto al ruido. A partir de

objeto de la investigación doctoral de la que este texto forma parte. El ruido, según el enfoque disciplinario, o la perspectiva de quien escucha o el contexto de su aparición, puede definirse como una forma de violencia, como potencia sonora, como un intruso o como una expresión de la cultura. 
esta idea se construyó una tipología de "víctimas de ruido", cuya situación fue definida con base en su relación con cierto tipo de fuentes sonoras, como el caso de quienes viven o laboran cerca de una avenida con tránsito continuo, una zona de diversión nocturna, un estacionamiento, un hospital, un vecino ruidoso, cerca del Aeropuerto Internacional de la Ciudad de México o en una zona de obras.

Esta particularidad metodológica obedece a la necesidad de reconstruir la experiencia del "habitante de la Ciudad de México"; en este sentido, los individuos importan en la medida en que su experiencia es representativa de los habitantes de esta ciudad y no como caso individual. Con esto no se pretende decir que "la ciudad" es una elaboración unívoca, sino que existen vivencias que son comunes a muchos citadinos porque dan cuenta de situaciones, actores y escenarios cotidianos a los que todos, de una u otra manera, tenemos acceso. En todo caso, las diferencias se manifiestan no en una gama infinita de experiencias posibles en la ciudad, sino en la manera en que cada quien percibe ese número vasto pero limitado de episodios urbanos.

\section{Ser vecino del Aeropuerto Internacional de la Ciudad de México}

Hace un par de años tuve la oportunidad de entrevistar a una familia que vive en la colonia Cuchilla del Tesoro, una de las diecisiete que se localizan en las inmediaciones del Aeropuerto Internacional de la Ciudad de México, a escasos veinte metros de una de las bardas que delimitan este lugar. Mi interés al acercarme a ellos era conocer la experiencia de alguien que viviera muy cerca de una de las situaciones más problemáticas de las grandes ciudades -y muy particularmente de la Ciudad de México- en lo que respecta a la salud acústica: el tráfico aéreo. Tenía muchas expectativas con respecto a esta entrevista, esperaba encontrar a gente molesta, enferma y con una vida totalmente perturbada por los aviones. Para mi sorpresa, hallé un panorama totalmente distinto al que había imaginado: una familia que no sólo estaba perfectamente acoplada al ruido y al trajín del aeropuerto, sino que incluso parecía haber encontrado ventajas en ello.

La familia López había llegado a esa casa en el 2003. No fue un lugar que ellos escogieran para vivir, sino su única opción, porque se trata de un terreno familiar en donde se construyeron viviendas para los hermanos del señor López y sus respectivas familias. Cuentan que al principio les fue difícil lidiar con tanto ruido, pero que muy pronto 
se acostumbraron a él. El primer síntoma de perturbación lo notaron en su hijo, que para ese entonces aún no nacía:

Yo recuerdo que cuando estaba embarazada de mi hijo no vivíamos aquí pero estábamos acondicionando el departamento y veníamos una vez a la semana. Cada que veníamos pasaba el avión y yo sentía cómo se encogía en mi vientre, sentía el estómago duro como una bola y luego normal, se relajaba. Cuando ya llegamos a vivir aquí él tenía siete meses. Fue fácil que se acostumbrara; ya después no lloraba ni nada, al contrario, cuando él dormía sus siestas era más fácil que se despertara con la licuadora o con un ruidito menor que con los aviones. Para él era normal.

Tal como hice yo, muchas personas que los visitan por primera vez no pueden evitar preguntarles cómo es vivir ahí. Esta pregunta evidencia el hecho de que en el imaginario colectivo su situación de vecinos del aeropuerto es inconveniente, y que para nosotros sería prácticamente insoportable vivir bajo esas condiciones. Comenta el señor López que la gente que va a su casa suele taparse los oídos cada vez que pasa un avión y que es muy común que les pregunten: “‘pueden dormir?', y les decimos 'sí, sí podemos, tranquilamente, gracias a Dios no hay ningún problemita’. Pero todo es cuestión de que se acostumbre uno, y pues creo que ya superamos ese proceso, la parte difícil de esto”.

Nadie puede dejar de notar la intimidante cercanía de los aviones ni su estruendosa presencia. Para la familia López, sin embargo, los aviones son un elemento más de su paisaje sonoro cotidiano, una presencia que, a fuerza de costumbre, han aprendido a ignorar. A decir de la señora López, se trata de "un sonido normal, yo pienso que ya es parte del entorno, ya no es algo que le afecte a alguno". Esta estrecha relación que la familia López ha construido con el lugar en el que vive es evidente al observar el conocimiento que tiene del aeropuerto y su dinámica. El señor López, por ejemplo, identifica a los aviones tan sólo de oído, e incluso ha diseñado un sistema de cuatro categorías según la intensidad del sonido, mismo que me fue ilustrando durante la entrevista al paso de cada avión:

Bueno, yo no sé de aviones, yo solamente puedo identificar un avión, un jet, un Hércules, un Boeing 747, pero no un modelo. A partir de que vive uno aquí es como se aprende a identificar los aviones. El jet es pequeño pero es muy ruidoso y es veloz. El jumbo es más lento; cuando llegan a aterrizar se ve enorme arriba: “Ay Dios, guárdanos!”. Los Hércules son de carga pero son de hélice, entonces esos aviones producen un sonido 
que es estremecedor. No sé, se siente diferente. Yo no recuerdo haber escuchado al Concord, pero dicen que tomaba pista aquí mero enfrente; dicen que no hacía ruido, nomás producía un zumbido que lastimaba los oídos. A veces en la madrugada aterrizan particulares: una avioneta o un jet; esos sí producen un sonido muy fuerte porque van muy bajo, más que un avión comercial. Luego hay aviones que cimbran la casa, es un sonido posterior al paso del avión, al minuto viene una ráfaga de aire "zzzzzzzz", pero solamente cuando pasó muy bajo.

La familia también conoce la dinámica del aeropuerto. A decir de la señora López el tráfico es continuo y tiene como horas pico entre las 2:00 y las 4:00 de la tarde-aunque a su decir ella no se fija mucho en los aviones-. La actividad comienza en la madrugada, por ahí de las 4:00, y cuando hay neblina los vuelos se detienen. El señor López refiere así una parte del proceso de aterrizaje:

Cuando cambia el viento el aterrizaje es por aquel rumbo, por esos árboles que ve ahí enfrente, ahí es la Alameda Oriente, después está Netzahualcóyotl y de aquel lado está la colonia Arenal. Ahorita el tráfico está más de aquel lado, sobre Boulevard Aeropuerto. Ahorita han venido pocos a tomar pista por acá [...] Esos aviones que ve ahí dando vuelta están esperando hasta que les den pista, mientras se dan la vuelta por la Jardín Balbuena, la colonia Moctezuma, Pensador Mexicano y parte de Fray Servando. Esa zona de enfrente es la entrada de los aviones, la de más tráfico.

Resulta inevitable pensar en el costo de esa normalidad y en el tipo de afectaciones o adecuaciones que se han tenido que gestar para acostumbrarse a cosas tan extremas como un despegue o un aterrizaje cada dos minutos durante la mayor parte del día, la sacudida intermitente de pisos, paredes, vidrios y cosas colgadas de la casa, una presión sonora de más o menos 140 decibeles $^{3}$ y el ensordecimiento total al paso de cada avión.

Parte de la normalidad de vivir cerca del aeropuerto consiste en la incorporación del ruido a sus dinámicas cotidianas. Algunas veces

${ }^{3}$ El decibel es una unidad de medida de intensidad sonora y se representa con las siglas $\mathrm{dB}$. El oído humano posee un área de sensación auditiva que determina los límites de la escucha, y oscila entre $1 \mathrm{~dB}$-que es el umbral de audición, es decir, el sonido mínimo perceptible-y $140 \mathrm{~dB}$-el nivel máximo o umbral de dolor, es decir, el momento en que la experiencia sonora se vuelve sufrimiento-. La Organización Mundial de la Salud considera que la afectación al oído se comienza a producir a partir de los $65 \mathrm{~dB}$. Para conocer los decibeles que poseen algunos enseres y situaciones de la vida cotidiana, véase el cuadro 1 . 
Domínguez, VIVIR CON RUIDO EN LA CIUDAD DE MÉXICO

\section{CUADRO 1}

Decibeles de algunos enseres y situaciones de la vida cotidiana

\begin{tabular}{|c|c|c|}
\hline$d B$ & Sonidos & Efecto \\
\hline $1 \mathrm{~dB}$ & \multicolumn{2}{|c|}{ Umbral de audición } \\
\hline $10 \mathrm{~dB}$ & $\begin{array}{l}\text { Respiración tranquila } \\
\text { Lluvia fina } \\
\text { Cuchicheo } \\
\text { Susurro } \\
\text { Pisadas suaves }\end{array}$ & Normal \\
\hline $15 \mathrm{~dB}$ & Canto de un ave & \\
\hline $20 \mathrm{~dB}$ & $\begin{array}{l}\text { Biblioteca } \\
\text { Tic tac de un reloj }\end{array}$ & \\
\hline $40 \mathrm{~dB}$ & Plática entre dos personas & Bajo \\
\hline $50 \mathrm{~dB}$ & $\begin{array}{l}\text { Un lugar tranquilo } \\
\text { Conversación normal } \\
\text { Tráfico ligero }\end{array}$ & \\
\hline $60 \mathrm{~dB}$ & Grito & \\
\hline $65 \mathrm{~dB}$ & $\begin{array}{l}\text { Licuadora, batidora, televisión, } \\
\text { despertador }\end{array}$ & Irritación, dificultad para \\
\hline $70 \mathrm{~dB}$ & $\begin{array}{l}\text { Aglomeración de gente } \\
\text { Restaurante concurrido } \\
\text { Aspiradora } \\
\text { Oficina bulliciosa en horario de trabajo }\end{array}$ & $\begin{array}{l}\text { conversar; pérdida } \\
\text { de concentración y atención }\end{array}$ \\
\hline $80 \mathrm{~dB}$ & $\begin{array}{l}\text { Secadora de cabello } \\
\text { Reloj despertador } \\
\text { Conversación en voz alta } \\
\text { Timbre }\end{array}$ & \\
\hline $85 \mathrm{~dB}$ & Altavoces & Molestia, estrés, cansancio \\
\hline $90 \mathrm{~dB}$ & $\begin{array}{l}\text { Tránsito intenso } \\
\text { Aspiradora } \\
\text { Sala de cine }\end{array}$ & \\
\hline $95 \mathrm{~dB}$ & Vendedores / bocineros del Metro & \\
\hline $100 \mathrm{~dB}$ & $\begin{array}{l}\text { Discoteca } \\
\text { Claxon } \\
\text { Calle con ambiente nocturno } \\
\text { Banda música de rock } \\
\text { Audífonos a todo volumen }\end{array}$ & Molestia, nerviosismo \\
\hline $110 \mathrm{~dB}$ & $\begin{array}{l}\text { Martillo neumático en una obra } \\
\text { Concierto de rock } \\
\text { Motocicleta acelerando } \\
\text { Salones de videojuegos }\end{array}$ & Extremadamente fuerte \\
\hline
\end{tabular}


CUADRO 1

(concluye)

\begin{tabular}{|c|c|c|}
\hline$d B$ & Sonidos & Efecto \\
\hline & \multicolumn{2}{|c|}{ Umbral de dolor } \\
\hline $120 \mathrm{~dB}$ & $\begin{array}{l}\text { Juegos pirotécnicos } \\
\text { Alarma de automóvil }\end{array}$ & \\
\hline $130 \mathrm{~dB}$ & $\begin{array}{l}\text { Disparo de arma de fuego } \\
\text { Trueno } \\
\text { Martillo neumático }\end{array}$ & Dolor y daño \\
\hline $140 \mathrm{~dB}$ & Despegue de un avión & $\begin{array}{l}\text { Peligro de daño acústico; } \\
\text { dolor intenso }\end{array}$ \\
\hline $180 \mathrm{~dB}$ & Despegue de un cohete especial & $\begin{array}{l}\text { Pérdida auditiva irreversible } \\
\text { sin protección }\end{array}$ \\
\hline
\end{tabular}

FUENTE: Elaboración propia.

esta inclusión se realiza con toda la intención de aprovechar su presencia, como ocurre en las siguientes dos anécdotas que me refirieron los entrevistados: "Nos sucedió mucho que el niño se despertaba cuando echábamos a andar el motor de la camioneta. Entonces, para que no se despertara, esperábamos a que pasara un avión para echarla a andar y así ya no se daba cuenta”. La señora López aprovecha de igual manera la indiferencia de sus hijos ante el estruendo de los aviones y utiliza el ruido para enmascarar otros sonidos mucho menos intensos pero más molestos: "Si yo preparo algo de comer en las mañanas, para que no se despierten los niños espero a que se oiga el avión y prendo la licuadora. Igual en la noche aprovechamos el ruido del avión para hacer otras cosas. O sea el ruido nos ha ayudado, tiene sus ventajas, se las hemos encontrado".

En otras ocasiones, sin que la familia se lo haya propuesto, el ruido de los aviones los orilla a realizar ciertas adecuaciones a su dinámica cotidiana: "A veces estamos viendo las noticias, estamos oyendo algo interesante y viene el avión, entonces mueve la señal y no nos deja oír si es algo interesante; entonces estamos 'qué dijo, qué dijo' [...] y cuando sentimos que ahí viene le subimos todo el volumen a la televisión” (Sr. López, 2010). Es el mismo efecto de enmascaramiento que en el párrafo anterior suponía una ventaja, el que ha llevado a la familia a modificar ciertas dinámicas a partir de la presencia sonora de los aviones, un proceso que han construido inconscientemente en el día a día con el propósito de ajustarse a sus particulares condiciones de 
vida: "Yo por ejemplo estoy aquí y necesito algo y le hablo a los niños. Entonces a veces va pasando el avión y no veo respuesta de ellos, y entonces les tengo que volver a hablar. Luego el niño me dice algo y yo le digo: 'es que no te oigo, ya sabes que cuando pasa un avión no me hables porque no se oye'”.

Ciertamente, el efecto más notorio de la proximidad con el aeropuerto se produce en la dinámica de comunicación de la familia. La primera vez que hablé por teléfono con la señora López, justo cuando me estaba dando las indicaciones para llegar a su casa, perdí por completo su voz a causa de un fuerte zumbido; cuando éste pasó me di cuenta de que la señora había seguido hablando, pues me preguntaba si yo había entendido. Por supuesto le pedí que me repitiera su dirección pues algo le había pasado a mi teléfono. "No, fue un avión, es que pasan aquí cerquita", me dijo. Lo mismo ocurrió durante la entrevista, al paso de cada avión los dos seguían hablando, a pesar de que era imposible escuchar. Si consideramos que durante la primera hora pasaron 23 aviones, es posible imaginar la gran pérdida de información que hubo durante la entrevista. Tras esa hora que duró mi intento de lidiar con el ruido y acoplarme a la dinámica de mis anfitriones, opté por decirles que estaba teniendo dificultad para entenderlos y les pedí que hicieran una pausa al paso de cada avión para no perder el hilo de su discurso. Podrán imaginar la lentitud que adquirió entonces nuestra conversación. Al hacerles notar lo extraño que resultaba para mí esta forma de hablar, el señor López me dijo que eso mismo ocurría en la calle cuando se detenían a platicar con alguien y en la escuela de sus hijos, también colindante con el aeropuerto pero ubicada cuatro calles adelante: "Luego estamos en las juntas y pasa el avión y se guarda silencio, y cuando se va se retoma el tema, porque es la manera en que todos escuchamos, es la manera en que actuamos aquí en la colonia".

A raíz de esta entrevista he pensado mucho sobre la impresionante capacidad de adaptación de los seres humanos, que incluso en los entornos más difíciles encuentran maneras no sólo de adecuación, sino también de arraigo, tal como dice una vecina de la familia López: "Yo no cambio mi Cuchilla por nada, con todo y mis avioncitos que nos hacen ruido". Desde luego, el hecho de haberse acostumbrado al aeropuerto no impide que se reconozcan los riesgos que implica vivir ahí. Cuenta el señor López que tras el anuncio del cambio del aeropuerto a Texcoco pensó: “¿Qué bueno, bendito Dios que lo quiten!'. Ya después dijeron que no y pues bueno, ni modo. Hasta ahorita no 
ha pasado nada y esperemos que no pase nada. Sabemos que sí puede haber daño. Por ejemplo yo noto que tengo más audición en el oído izquierdo que en el derecho [...] pero yo creo que es la necesidad de estar en un lugar, yo creo que por eso la gente se adapta”.

Efectivamente, en muchos de los casos de gente que vive peligrosamente expuesta al ruido, es la necesidad de trabajo o de vivienda la razón por la cual se termina aceptando resignadamente dicha situación. El ruido es uno más de los riesgos de vivir en la ciudad, y en todo caso se considera como un problema menor frente a otro tipo de condiciones de vulnerabilidad ocupacional y de vivienda:

Yo pienso ahora en las inundaciones. La gente sabe que hay ese tipo de riesgos pero uno construye sus casas en base a la necesidad. Y yo pienso que a lo mejor ellos dicen de nosotros: “¿cómo es posible que vivan ahí?”, nos comentaba un muchacho de la gente que vive en el cerro y el riesgo de los deslaves. Yo creo que algunos padecen por el agua, por estar cerca de un río o un canal, la gente que vive en los cerros, y otros por el ruido. Entonces yo creo que de alguna u otra manera hay problemas, siempre estamos expuestos a un riesgo [Señora López, 2010].

No todos los casos relacionados con el asunto del ruido y el aeropuerto son como el de la familia López. Existen quienes manifiestan abiertamente su desacuerdo ante la presencia del AICM en su vida cotidiana; incluso se han dado algunos intentos de denuncias, todos ellos infructuosos, emprendidos por vecinos que se dicen fuertemente afectados por el ruido. Uno de los casos más tenaces fue el promovido por una asociación de colonos de la colonia Jardín Balbuena, que se organizó en 2001 en torno a una lucha contra el ruido del aeropuerto. Tras presentar sin éxito dos "denuncias populares" ante la Procuraduría Ambiental y de Ordenamiento Territorial y la Secretaría del Medio Ambiente del Distrito Federal, en 2002 recurrieron a la Comisión para la Cooperación Ambiental con sede en Canadá, solicitando su intervención para hacer cumplir a las autoridades mexicanas las normas ambientales relativas a las emisiones de ruido, con base en el Acuerdo de Cooperación Ambiental de América del Norte (ACAAN).

Los vecinos, a sabiendas de que la única manera de solucionar el problema era el traslado del aeropuerto, demandaban que al menos se implementaran acciones para mitigar el ruido. En su petición expusieron las afectaciones que este problema produce en su salud y bienestar: 
Las emisiones de ruido [...] han causado en nuestras personas, en nuestras familias, y en las miles de personas que vivimos en la periferia del AICM daños al sistema auditivo [...] Los problemas de salud que padecemos algunos de los peticionarios y de los miembros de nuestras familias no son casos excepcionales o aislados, sino una muestra de los riesgos a los que todos los vecinos del AICM estamos expuestos.

Los signantes de esta petición se presentan como: "Personas que radicamos en las inmediaciones del AICM. Todos hemos residido en la zona circundante del AICM durante la mayor parte de nuestras vidas y algunos incluso durante toda su vida". Resulta curioso observar que a diferencia de la familia López, que no lleva ni una década en esa colonia y se ha acoplado perfectamente a la dinámica del aeropuerto, los miembros de esta asociación no sólo no han logrado acostumbrarse al ruido tras varias décadas de vivir en el mismo lugar, sino que esta relación permanente ha incrementado su repulsa hacia ese estímulo.

\section{La habituación}

La vida cotidiana, aquella en la que nos encontramos sumergidos, tiene como proceso fundador a la habituación, es decir, un mecanismo de adaptación que nos permite incorporar paulatinamente a nuestra vida diaria los fenómenos de nuestro entorno hasta volverlos parte de nuestra normalidad. Bruce Bégout define a la habituación como una técnica antropológica de cotidianización, a través de la cual el ser humano va asimilando el mundo que lo rodea hasta convertirlo en un lugar familiar: "Cotidianizar es, entonces, asimilar día tras día el mundo hostil, a través de todo un filtro de creencias y de objetos, de símbolos y costumbres que dan control sobre la realidad [...] es una operación cuasi metabólica de ajuste entre el individuo y su medio" (Bégout, 2005: 313).

Eric Kandel, premio Nobel de Fisiología y Medicina en el año 2000 por sus estudios fisiológicos sobre la memoria, describe el proceso de habituación como la forma más sencilla de aprendizaje, mismo que funciona a través de "una disminución de la respuesta conductual que resulta de la presentación del estímulo inicial [...] en aprender a identificar e ignorar estímulos que han dejado de ser novedad y han perdido significado" (2007: s/p). En contraposición, hay quienes estando sometidos al mismo estímulo no pueden ignorarlo y por lo 
tanto son incapaces de incorporarlo a su cotidianidad, es decir, se vuelven sensibles al estímulo y viven constantemente alterados por su presencia. ${ }^{4}$ Este mecanismo contrario se llama "sensibilización", y supone "aprender a aumentar una respuesta refleja determinada como resultado de un estímulo perjudicial o nuevo" (Kandel, 2007: s/p).

Es precisamente este proceso dual de habituación-sensibilización el que nos permite comprender las dos reacciones contrarias que existen entre los habitantes de las inmediaciones del aeropuerto, y en general las disimilitudes que llegan a existir en la percepción de cualquier estímulo. Esta dualidad equivaldría a algo semejante a volverse inmune o alérgico al ruido, siendo la inmunidad la condición más deseada -porque evita el sufrimiento- pero también la conducta más anormal porque supone una atrofia del sentido de la escucha para poder adaptarse al entorno.

Hablando de ruido es muy común escuchar entre los habitantes de la Ciudad de México la respuesta: "Ya me acostumbré", cuando se le pregunta a alguien sobre cómo hace para vivir sobre avenidas altamente transitadas, o con una fábrica a un costado de la casa, o en el piso que está justo arriba de un bar. En muchos casos la gente refiere que tras un periodo de extrañeza debido a la aparición de un nuevo sonido, se termina por aceptar el ruido. Este fenómeno suele ir ligado al comienzo de una nueva experiencia -nuevo trabajo, nueva residencia, nuevos vecinos o nueva rutina- a la que el oído debe acostumbrarse. Conforme a la lógica de Kandel podemos decir que estas personas, a fuerza de repetición y contacto, aprenden a vivir con dichas presencias hasta el punto de lograr que pasen prácticamente desapercibidas. Bégout (2005) refiere que la posibilidad de aprender a ignorar un estímulo es un ejemplo de "el poder coagulante del hábito"; a esto se debe que haya quien no reacciona ante un estímulo muy notorio, pero en cambio se altera por una sonoridad mínima, como en el caso que nos cuenta el señor López, vecino del aeropuerto, quien dice que a diferencia de lo que le ocurre con el rugido de los aviones, existen sonidos que sí le quitan el sueño:

En casa de mi papá tienen un péndulo, y cuando lo visito ese sonido no me deja dormir, doy vueltas y vueltas. Luego en el patio tienen un refrigerador de paletas y me inquieta cuando se enciende el motor. Yo creo

${ }^{4}$ Es esta cualidad de extrañeza, de no invitado, la que convierte a un sonido en ruido, haciendo de este término un adjetivo con el cual se designa cualquier elemento sonoro que pone en peligro la disposición personal de nuestro mundo privado. 
que es porque no son parte de nuestros sonidos que ya registramos y eso le impide a uno conciliar el sueño. Son cosas a las que ya estamos habituados o cosas que nos desequilibran.

Aprender a anular un sonido es uno de los efectos de la habituación. A este mecanismo le debemos que ciertos sonidos como las alarmas o el claxon se hayan convertido en sonidos residuales, es decir, en una suerte de deshecho sonoro que, por su presencia excesiva y la sobreestimulación que ejerce en el escucha, ha perdido su capacidad de comunicar. También nos permite entender por qué los vendedores del Centro Histórico de la Ciudad de México pueden permanecer aparentemente imperturbables más de seis horas en medio de un constante griterío de oferentes de productos, o la razón por la cual los trabajadores de los centros de diversión nocturna dicen no notar los altos volúmenes de la música ambiente de esos lugares, o por qué un agente de tránsito aguanta impasible ocho horas en medio del tráfico citadino. En cierta ocasión, mientras acompañaba a una comisión de la PAOT a realizar una medición de ruido en el primer cuadro de la ciudad, nos detuvimos a platicar con un agente de tránsito cuyo silbato había registrado cerca de 95 decibeles. Le preguntamos si acaso el sonido de su silbato le había dañado el oído. "¿Qué?”, nos contestó gritando, a pesar de que estábamos frente a frente. "Que si ha notado algún daño a su oído", repetimos. "Ah no, yo oigo muy bien”. Durante algunas entrevistas me ocurrió que al preguntar a la gente sobre cómo era vivir cerca de una trepidante bomba de agua o sobre uno de los sistemas de refrigeración de un Oxxo, cuya potencia sonora les impedía pasar desapercibidos, la gente parecía sorprendida y me respondía cosas como: "Nunca había pensado en eso" o "¡Uy!, hasta ahorita que me dice, no me había dado cuenta".

\section{El horror vacui}

Uno de los efectos más comunes de la habituación, y que aparece como uno de los rasgos entre quienes habitan las ciudades, es la sensación de que "algo" les falta cuando se encuentran lejos de ellas y por lo tanto del ruido: "Nosotros hemos viajado a provincia y notamos la diferencia, la tranquilidad, y como que somos hijos de la mala vida. Estamos en la pasividad y extrañamos el bullicio; estamos en la tranquilidad y extrañamos los tumultos. Hay gente que dice: 'yo no cambio 
mi vida de la ciudad por la vida de provincia'. Todo es cuestión de habituación" (S., entrevista, 2010).

Un oído que se ha habituado al bullicio urbano necesita del ruido para no extrañarse, para sentirse a gusto, para poder realizar sus actividades con normalidad. Mucha gente dice no poder conciliar el sueño cuando se encuentra en el campo o en lugares sonoramente menos saturados que la ciudad. En cierta ocasión un profesor me dijo que había considerado grabar el sonido del tráfico para llevarlo a los campamentos que realizaba fuera de la ciudad con sus hijos, para así "sentirse como en casa". La necesidad de ruido y la repulsa de su ausencia fue bien descrita por uno de mis entrevistados como horror vacui:

La gente le teme al silencio, le tiene horror a la tranquilidad [...] entonces este horror se compensa con lo opuesto, es decir, con volver ruidosa la música o volver ruidosa la televisión. Casi no podría mencionar un restaurante o un espacio de convivencia pública que no esté invadido por la televisión o la música en esta idea de amenizar, divertir o pasártela bien. Y otra, y eso lo comprobé recientemente, si estás en una reunión y no hay música, lo que sea, hay como un sentido de carencia [Iván E., entrevista, 2010].

Horror vacui literalmente significa "miedo al vacío". Se trata de un concepto que ha orientado diversas tendencias de la ciencia, el arte y el pensamiento, y que alude básicamente a la sensación de angustia que se experimenta frente al vacío y cualquiera de sus metáforas: la desnudez, la simplicidad o el silencio. Es comprensible que para el habitante de la ciudad, acostumbrado a la saturación del paisaje sonoro que lo obliga a tener los oídos siempre llenos, el silencio resulte un estado poco soportable porque remite a una ausencia sonora. A esto se debe el hecho de que, si bien muchos sonidos pasan desapercibidos por efecto de la habituación, éstos se vuelven a hacer notorios cuando desaparecen. Bruce Bégout explica cómo es que lo cotidiano, lo que se ha vuelto invisible, lo que ha dejado de significar, vuelve a cobrar importancia para quien lo habita: "lo cotidiano sólo se revela como tal si lo oponemos a aquello que no lo es, es decir, se distingue por contraste. Es en relación con el otro que lo cotidiano se ilumina" (2005: 73).

Revisemos a continuación un caso que ha derivado en esto que hemos llamado horror vacui, y que ilustra muy bien la relación entre la exposición constante al ruido y el proceso de habituación. Se trata de la señora Alejandra, trabajadora de una tienda de autoservicio, quien nos cuenta cómo se modificaron sus hábitos auditivos tras ocho años 
de labor en dicha empresa y de una exposición continua a estímulos sonoros:

Tenemos un horario rolado que puede ser de 6 de la mañana a 3:30 de la tarde o de 2 a 10:30 de la noche, o puede ser intermedio. Son nueve horas en total y en esas nueve horas no hay un solo momento en silencio. Es el bullicio de la gente, siempre hay mucha gente, siempre están preguntando "en dónde está esto, en dónde está lo otro". Entonces estamos con el oído atento a todos los sonidos, nos están hablando para preguntarnos algo o alguno de nuestros jefes nos habla para que vayamos a ver algunas cosas. Aparte está también el ruido del equipo de trabajo, porque meten mercancía con patines, el piso no es de loza sino de cemento, entonces cuando llevan el patín con la mercancía también hacen mucho ruido, van golpeando y rechina.

Además tenemos el sonido local en donde se pone música ambiental dependiendo de la temporada. Por ejemplo, ahora que va a ser temporada navideña comienzan a poner música de Navidad; pero ahorita que se están festejando los cincuenta años de la empresa, pues ponen música alegre, de fiesta. Aunado a esto está el voceo local que anuncia las ofertas, lo que se está vendiendo en ese momento, o que equis encargado de departamento vaya a cajas. El voceo es constante. Yo estoy en Hogar y en Electrónica. Ahí tenemos que tener prendidas las teles, todas las teles del área con un solo canal o un DVD que está todo el día. Anteriormente yo estaba en Farmacia. Ahí el trato es personalizado y a veces tenemos clientes que son de edad avanzada y no escuchan bien; el mismo voceo no los deja escuchar.

También hay una alarma que suena en el momento en que se abren unas vitrinas electrónicas si no la apagan rápido. Me acuerdo que en un principio, cuando sonaba, era muy aguda y me molestaba, pero ahorita no. Esa alarma se prende todo el día, lo que se venda se tiene que sacar de ahí; en un turno suena por lo menos unas quince o veinte veces. Una vez pusieron una pantalla en donde se proyectaban comerciales de lo que se vende, y la teníamos exactamente arriba de la caja registradora; entonces era la caja que hace ruido, más la música local, más lo que estaba en la pantalla, más el voceo. La gente se quejaba: “¿le pueden bajar?”, “¿qué precio tiene?, no la escucho”, “¿me puede repetir?”. En ese momento sí se volvió un problema.

Esta entrevista fue concertada a través de una alumna, al solicitar a mi grupo su ayuda para recopilar testimonios de personas que tuvieran problemas de oído ocasionados por el ruido. Al terminar la clase, la hija de la señora Alejandra se acercó y me dijo que creía que su mamá se estaba quedando sorda, que en su casa tenían problemas de 
comunicación porque su mamá no escuchaba, y que suponía que la causa de todo era su trabajo. El día de la entrevista, la señora Alejandra comenzó diciéndome que a partir de que su hija le había comentado sobre mi trabajo había pensado mucho sobre su situación: "antes nunca me había puesto a pensar sobre el ruido”. Pensaba que si su hija le había sugerido hablar conmigo era porque estaba preocupada por su salud y porque era evidente que algo no estaba funcionando bien y que todos, excepto ella, lo habían notado. Me dijo que en esas dos semanas -tiempo transcurrido hasta el día de la entrevista- se había puesto a pensar sobre su situación en el trabajo y la manera en que éste le había afectado a través del tiempo:

Yo me acuerdo que antes para dormir tenía que ser todo a obscuras y sin sonido. Ahora ya no, inclusive me puedo quedar dormida estando la televisión prendida; muchas veces la tengo que prender para dormir. Es así como algo para arrullarme. Ahora que me decía mi hija de la televisión, le dije: "pues es que no me había puesto a pensar en que estoy viviendo en una contaminación tan fuerte que está pasando a ser algo cotidiano para mí”. Y no digo que no me esté haciendo daño, porque yo creo que sí me está haciendo daño, se está volviendo así como una adicción, pero es algo que pasa inadvertido. Hoy día no, no puedo, aunque no esté viendo la televisión, pero tiene que estar prendida. Ha habido ocasiones en que yo misma me sorprendo. Si me salgo de esta habitación y me voy a otra prendo otro aparato. Ahora necesito esa variante de tener el ruido a alto nivel para poder entender. Generalmente tengo encendida la televisión. Como nos reunimos ya hasta la noche y estamos los cuatro y está la televisión, y ellos platicando o con la computadora. Y si bien es cierto que ellos se ponen los audífonos para escuchar la computadora, se escucha ese zumbido que está en la sala.

Entonces es el hecho de tener otra vez ese ruido. Para mí es a veces un tanto necesario, porque yo he estado en casa sola y necesito tener algo prendido. Igual y puedo estar atenta a lo que ellos [sus hijos] están platicando pero necesito que esté muy fuerte la televisión para escucharla o el radio. Ellos me dicen: "mamá, es que está muy alto". "Pues sí, pero es que no escucho", les digo. El silencio, en vez relajarme o de hacerme sentir a gusto, como que me hace sentir cierta angustia, como que empiezo a sentir que algo me está faltando. He notado que me he vuelto muy nerviosa, a veces un tanto agresiva, no es algo que yo perciba en el momento: "no estoy enojada, así hablo". Me altera que me hablen muy de cerca, no aguanto el sonido tan cercano, sin importar el volumen.

Desde que trabajo ahí ha sido un cambio radical. Al principio sí me molestaba, recuerdo que todos esos ruidos sí me molestaban; decía yo: “cuándo van a apagar el sonido del voceo. Basta, tengo que salir porque 
no logro aguantar esto". Y yo veo que fue muy rápido este proceso [de habituación] por lo mismo que estamos tan adentrados en el trabajo. Yo creo que es porque ahí el tiempo se pasa tan inadvertido, estamos tan ocupados que no sentimos. De que yo no aguantaba una música de alto nivel, ahora hasta pedirla, porque no es que no la escuche, sino que la necesito. Ahora ya estoy habituada a los sonidos molestos, hoy en día ya lo veo normal. En mi trabajo tengo que prender como cuatro oídos para escuchar todo. Pero yo creo que sí, que todos modificamos nuestra forma de ser al entrar a trabajar ahí.

La tendencia de la vida urbana a la saturación de los ambientes -públicos, privados, de trabajo y de esparcimiento- ha provocado que el ruido se convierta en una necesidad, tal como le sucede a la señora Alejandra, quien a lo largo de su vida ha modificado negativamente sus hábitos de escucha en un ánimo de adaptación a ambientes un tanto adversos. Las condiciones a través de las cuales alguien llega a habituarse al ruido son de índole muy diversa y dependen de los hábitos y la sensibilidad de cada persona; sin embargo, lo que está de por medio en este proceso es una exposición constante al ruido que permite no sólo incrementar la resistencia ante ciertos estímulos, sino sufrir su falta.

Quien padece el horror vacui sonoro evita a toda costa el silencio y pone en marcha diversos recursos que devienen hábitos, encaminados a llenar los espacios en blanco. Tal vez esta poca tolerancia al silencio permita explicar esa tendencia a sonorizar los enseres de la vida cotidiana: los teléfonos, los hornos, las puertas, los apagadores y casi todos los accesorios que procuran comodidad y bienestar; o la costumbre tan expandida de utilizar la televisión y la radio como sonido de fondo. De la misma manera podríamos comprender el éxito de las tecnologías portátiles de reproducción de música, que ofrecen la posibilidad de mantener a los oídos siempre ocupados y aislados en una sonoridad permanente y controlada; o el abuso del teléfono celular para sentirse siempre acompañado, aunque sea virtualmente.

En esta lógica de evitar el vacío sonoro podemos ubicar a la música ambiental que comúnmente encontramos en los restaurantes, las tiendas, los centros comerciales, las salas y pasillos de aeropuertos, oficinas y consultorios. Esta música tiene como antecedente la llamada "música de mobiliario" ( musique d'ameublement) concebida a principios del siglo XX por el célebre compositor francés Erik Satie, cuya intención era lograr un género musical que pasara desapercibido y que sirviera como fondo sonoro para ciertas situaciones de la vida cotidiana. El 
pintor Fernand Léger refiere la anécdota que hizo a Satie concebir este concepto musical. Cuenta que en cierta ocasión, mientras él, Satie y otros amigos desayunaban, se vieron obligados a abandonar el comedor a causa de una música escandalosa e insoportable; cuando dejaron el lugar Satie les dijo:

Es necesario crear una música de mobiliario, es decir, una música que sea parte del sonido ambiente, que lo considere. Yo la imagino melodiosa, suavizando el ruido de los cuchillos, de los tenedores, sin dominarlos, sin imponerse. Ella servirá para llenar el silencio, pesado a veces entre los comensales. Ella los liberará de las banalidades, neutralizará los ruidos de la calle que entran sin discreción [Salvador, 2008].

Esta música de decoración es conocida actualmente como Muzak, genérico que se adopta a partir de la fama cobrada por la empresa que lleva este mismo nombre y que se dedica profesionalmente a la programación musical. Pareciera, sin embargo, que en México se es programador nato, pues tal como refiere el testimonio que hace alusión al horror vacui, prácticamente no hay negocios, ni puestos callejeros, ni unidades de transporte colectivo que no tengan la iniciativa de cubrir sus espacios con un fondo sonoro programado, ni reunión o familia que no cuente con un DJ. Si se les pregunta a quienes fungen como programadores por qué es necesaria la música, contestarán algo parecido a "la música pone ambiente". Efectivamente, la intención es crear una atmósfera y con ello delimitar acústicamente un espacio.

Desde luego, aquello que lleva a la gente a necesitar el ruido no es el ruido en sí mismo, sino lo que éste representa. Poco se ha hablado sobre las bondades del ruido, tal vez porque éstas lo son sólo imaginariamente, sin que con esto se puedan evitar, reducir o contrarrestar los daños que ocasiona; sin embargo, para quien se ha acostumbrado a él, es una compañía, pues su presencia suele anunciar actividad humana. El ruido también brinda seguridad al protegernos de los entornos extraños. Respecto de esta capacidad protectora, David Le Breton comenta:

El ruido se suele identificar claramente con un origen, el silencio inunda el espacio y deja el significado en suspenso a causa de su poder ambiguo para expresar mil cosas a la vez. Una casa ruidosa tranquiliza pues priman las conversaciones, los juegos de niños, una radio encendida en un rincón del aparador, un grifo abierto para lavar la vajilla, una llamada que se abre paso a través de varias habitaciones [2006: 121]. 
Gracias a su poder de enmascaramiento el ruido oculta y sirve como escudo, cualidad que suele ser utilizada en los procesos de comunicación interpersonal en los espacios públicos para resguardar las conversaciones tras el manto del bullicio urbano.

\section{Habituarse o dejar de escuchar}

El ruido es un fenómeno que se construye casi por completo en los territorios de la percepción; es decir, son factores tales como el gusto, el estado de ánimo o el momento y el lugar de aparición de un sonido, los que determinan su grado de negatividad. Pese a esto, no debemos olvidar que el sonido posee características físicas y por lo tanto naturales, que lo pueden convertir, por sí mismo y más allá de las subjetividades y particularismos culturales, en un elemento perturbador, capaz de generar sensaciones ansiógenas y de riesgo que impactan directamente al cuerpo.

Los expertos en enfermedades del oído explican que uno de los primeros indicadores de daño auditivo por exposición al ruido es, precisamente, la falta de reacción ante ciertos estímulos sonoros; esto quiere decir que habituarse al ruido no sólo implica que se ha aprendido a ignorarlo, sino que el oído ha reducido su capacidad de escucha. Robert Alex Baron explica cómo es que se da este proceso:

Con demasiada frecuencia oímos este comentario: "al principio, el ruido me molestaba, pero ya me acostumbré a él”. Lo que el interlocutor quiere decir es sólo que su conciencia se redujo o desapareció completamente. El hombre no se acostumbra al ruido. En algún lugar del cuerpo humano el ruido se está absorbiendo a un precio desconocido. Ésta es la ley de la conservación de la energía [1980: 73].

La disminución de la capacidad auditiva a causa de la exposición a sonidos perjudiciales se denomina hipoacusia inducida por ruido (HIR), y su afectación va desde ligeras alteraciones hasta la pérdida total del oído, según la intensidad del sonido y el tiempo que se permanezca expuesto a él. La HIR es uno de los riesgos más comunes de salud ocupacional entre los profesionales de la música, y entre los oficiales, soldados y civiles que laboran en ambientes militares. De acuerdo con la Coordinación de Salud en el Trabajo del Instituto Mexicano del Seguro Social (véase Loera y Santiago, 2006), la HIR es una de las principales causas de enfermedad de trabajo entre los afi- 
liados al IMSS; según un estudio realizado por esta entidad donde se analizan los casos de enfermedad diagnosticados durante once años -de enero de 1992 a diciembre del 2002-, de las 52525 enfermedades de trabajo registradas en ese periodo, 11881 corresponden a traumas acústicos crónicos provocados por la exposición de los trabajadores a altos niveles de ruido. Los sectores más perjudicados corresponden a la extracción de minerales, las industrias metálica y textil, la construcción y ensamblaje de autopartes, y el transporte terrestre.

La atención sobre los problemas auditivos ha sido históricamente acaparada por el ámbito laboral; sin embargo, de manera más reciente, se ha comenzado a prestar atención a las lesiones auditivas provenientes de otros ámbitos de la vida cotidiana que han dado lugar a una nueva categoría de sordera denominada "socioacusia", definida como el déficit auditivo provocado por la exposición a ambientes ruidosos. Si este aspecto no ha merecido suficiente atención es porque no se suele pensar en el efecto acumulativo del ruido o en la exposición prolongada a diversas fuentes sonoras que, si bien pueden no poseer una gran potencia, mantienen el oído siempre ocupado y no permiten su descanso. Acerca del costo a la salud que cobran los ambientes ruidosos, Itzalá Rabadán Malda, especialista en acústica del Instituto Politécnico Nacional, habla sobre el riesgo al que se exponen quienes habitan en las proximidades de los aeropuertos: "normalmente el ruido en colonias aledañas de un avión al acercarse a la pista puede registrar frecuencias hasta de $140 \mathrm{~dB}$, lo cual resulta molesto y hasta doloroso, pues cuando pasamos de 120 dB a 123 dB quiere decir que se aumentó al doble la potencia del sonido, entonces se duplica el golpe para el tímpano” (Milenio, 2010).

Ciertos hábitos modernos han comenzado a preocupar a los estudiosos. Rabadán Malda explica que el uso prolongado de los reproductores de música y la escucha de altos decibeles dañan seriamente la audición: "Las generaciones anteriores tendrán problemas de sordera propios de la edad, alrededor de los 60 años, pero en el caso de las actuales generaciones los pueden presentar desde los 45 años, es decir, que están adelantando 15 años un defecto que era propio de la tercera edad" (Milenio, 2010). Al respecto, la doctora Alma Pesquera Romero, coordinadora del área de Audiología y Otoneurología del Hospital General Regional núm. 1 "Carlos MacGregor Sánchez Navarro" de la Ciudad de México, informa que el uso desmedido de audífonos para escuchar música por más de 10 horas ha provocado que más de 19 millones de mexicanos de entre los 15 y 24 años de edad tengan afectaciones en los oídos (El Universal, 2009). 
La pérdida de audición es considerada por los expertos como un "mal de la civilización" por haber nacido como problema de salud pública por efecto de la Revolución Industrial, y por acentuarse como resultado de la velocidad y la comodidad de la tecnología. Murray Schafer identifica dos episodios históricos marcados por revoluciones tecnológicas, a través de los cuales la modernidad deja su impronta en el paisaje sonoro actual y en el oído de los habitantes del mundo. El primero de ellos es el motor de combustión interna aparecido en 1900, responsable de la sobrepoblación de automóviles en las ciudades, y en general de los medios de movilización -motocicletas, camiones, tractores y aviones- de la civilización contemporánea. El otro momento es la aparición de la electricidad, cuya masificación es responsable de la electrificación de la vida cotidiana, la multimotorización de los quehaceres, el incremento de las fuentes sonoras y la amplificación y potenciación del sonido.

Schafer (1979) explica que el ruido ambiente de las ciudades modernas, caracterizado por la sobrepoblación sonora, se eleva alrededor de un decibel por año, y que a lo largo de la historia se ha ido modificando el espectro auditivo de los seres humanos, con una tendencia a la ampliación de los umbrales de audición y de dolor o soportabilidad, hasta llegar en la actualidad a cubrir casi la totalidad del campo de audición humano. Robert A. Baron dice al respecto:

En su prodigalidad para con nosotros, la dadivosa naturaleza nos facilitó la pérdida inicial de la capacidad de oír frecuencias más elevadas. Esto significa que el primer castigo del ruido excesivo es la pérdida de la capacidad de gozar los sonidos bucólicos y la gama completa de los tonos musicales [1980: 80].

La Organización Mundial de la Salud estima que un tercio de la población mundial y el $75 \%$ de los habitantes de las ciudades industrializadas padecen algún grado de sordera por efecto del ruido. Señala también que unos 7 millones de personas mueren anualmente a causa de males cardiacos en el mundo, que 210 mil de esos casos se atribuyen al ruido excesivo, y que alrededor de 35 millones de personas en Europa están expuestas a niveles perjudiciales de ruido. Según la Organización Panamericana de la Salud, en América Latina poco más de $17 \%$ de los trabajadores con jornadas de ocho horas diarias durante cinco días a la semana con una exposición que varía entre 10 a 15 años padece de hipoacusia. 
La tendencia a la densificación de los entornos urbanos a través de la multiplicación de fuentes sonoras y la potenciación acústica ha provocado que, en una suerte de proceso mimético, el oído de los habitantes de las ciudades se haya hecho a la forma y capricho de su ambiente, necesitando al ruido para desenvolverse con soltura. La habituación ha costado a la gente la atrofia de unos sentidos; hay quienes piensan que éste es el precio del progreso.

\section{Conclusión}

El ruido como problemática social y de salud pública en la Ciudad de México es una preocupación reciente. Muestra de ello es el número creciente de quejas y conflictos por sonoridades indeseables que se ventilan, sobre todo, en foros públicos de internet o de viva voz, como: la urgente demanda de la creación y el cumplimiento de vías legales para resolver problemas de ruido relacionados con los horarios de cierre y apertura de comercios, la reglamentación de la publicidad sonora, la utilidad del claxon y la exigencia de una limpieza pública para echar a los vagoneros del Metro y retirar a los ambulantes de las calles. En este mismo tenor aparecen algunos reclamos vecinales encaminados a delimitar los derechos y las obligaciones propios de la cohabitación, y a hacer valer las leyes de ordenamiento territorial con la intención de mantener a las viviendas lejos de las fábricas y cierto tipo de comercios.

En el marco de estas nuevas exigencias ciudadanas no sólo está implicado el ruido, sino muchos otros asuntos que se encuentran en medio de una lucha de intereses y de definición de fronteras entre lo público y lo privado. Tal es el caso de la apropiación de las banquetas, el estacionamiento en la vía pública, la ocupación de las plazas y los parques, el cierre de avenidas, la basura en las calles, el conflicto entre conductores y peatones y de manera reciente entre automovilistas y ciclistas, la proliferación de los vendedores ambulantes, el descuido de las áreas comunes en los condominios, los eludidos gastos de mantenimiento y el horario de las fiestas.

La reciente incursión del ruido dentro de la lista de problemas que preocupan a los habitantes de la Ciudad de México nos hace pensar en la gestación de una nueva sensibilidad colectiva que apela a un proceso civilizatorio -definido por Norbert Elias como un cambio a gran escala en la estructura social afectiva- en tanto vemos aparecer 
una sociedad cada vez más quisquillosa que está transformando sus parámetros de agrado y desagrado, un aumento de sus escrúpulos en relación con los límites de su espacio privado, nuevas exigencias de respeto hacia lo público, y la aparición de un discurso contra el ruido que apela a la civilidad, al sentido común y a la conciencia colectiva. La materialización de estas pautas emotivas constituye, en su conjunto, una estructura afectiva social en ciernes relativa al ruido entre los habitantes de la Ciudad de México.

\section{Bibliografía}

Baron, Robert Alex (1980), La tiranía del ruido, México, FCE.

Bégout, Bruce (2005), La découverte du quotidien, París, Allia.

Espinosa, Víctor (2009), "Violan norma de ruido antros y bares de la delegación Benito Juárez", El Universal del Valle, 22 de diciembre. Disponible en <http:/ / www.eluniversaldelvalle.mx/detalle1292.html>.

Kandel, E. (2007), Psiquiatría, psicoanálisis y la nueva biología de la mente, Barcelona, Ars Médica.

Le Breton, David (2006), El silencio, Madrid, Sequitur.

Loera, María y S. Santiago (2006), "Hipoacusia por trauma acústico crónico en trabajadores afiliados al IMSS, 1992-2002”, Revista Médica del Instituto Mexicano del Seguro Social, vol. 44, núm. 6, pp. 497-504. Disponible en <http:/ / www.medigraphic.com/pdfs/imss/im-2006/im066b.pdf >.

Milenio (2010), "Sonidos modernos provocarán sordera a partir de los 45 años", Milenio, 10 de noviembre. Disponible en <http:/ /impreso.milenio.com/ node/8717280>.

Salvador, David (2008), "Musique d'ameublement, ou le nouveau statur de la musique", en: <http://musiquesetidees.blogspot.com/2008/03/la-musiquedameublement-ou-le-nouveau.html > (11 de marzo de 2008).

Schafer, Murray (1979), Le paysage sonore, París, JCLattès.

Simmel, George (1988) [1977], "La metrópolis y la vida mental”, en M. Bassols, R. Donoso et al. (comps.), Antología de sociología urbana, México, UnAM.

\section{Acerca de la autora}

Ana Lidia M. Domínguez Ruiz es profesora de tiempo completo de la Universidad Pedagógica Nacional y cofundadora del proyecto de información sonora Ruido S.O.S. Es doctora en Ciencias Antropológicas por la UAM- Iztapalapa, con la tesis "La naturaleza sonora de la vida urbana. Ruido, convivencia y conflicto por el espacio sonoro en la 
Ciudad de México"; maestra en Antropología Social por la ENAH, y licenciada en Ciencias de la Comunicación por la UDLA-P. Es autora del libro La sonoridad de la cultura. Cholula: una experiencia sonora de la ciudad (Miguel Ángel Porrúa / UDLA-P, 2009) y de varios artículos sobre cultura urbana, sociología de los sentidos y antropología del sonido. Pertenece al Sistema Nacional de Investigadores. 